\title{
Epidemiology of systemic sclerosis: a multi-database population-based study in Tuscany (Italy)
}

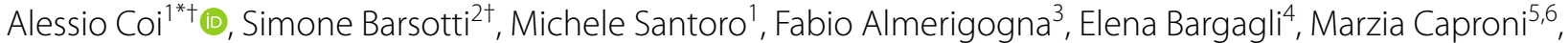 \\ Giacomo Emmi ${ }^{7}$, Bruno Frediani ${ }^{8}$, Serena Guiducci ${ }^{9}$, Marco Matucci Cerinic ${ }^{9}$, Marta Mosca ${ }^{2}$, Paola Parronchi ${ }^{7}$, \\ Renato Prediletto ${ }^{1,10}$, Enrico Selvi ${ }^{11}$, Gabriele Simonini ${ }^{12}$, Antonio Gaetano Tavoni ${ }^{13}$, the Rare Diseases Working \\ Group, Fabrizio Bianchi ${ }^{1,10}$ and Anna Pierini $i^{1,10}$
}

\begin{abstract}
Background: Systemic Sclerosis (SSC) is a chronic autoimmune disease with a complex pathogenesis that includes vascular injury, abnormal immune activation, and tissue fibrosis. We provided a complete epidemiological characterization of SSc in the Tuscany region (Italy), considering prevalence and incidence, survival, comorbidities and drug prescriptions, by using a multi-database population-based approach. Cases of SSc diagnosed between 1st January 2003 and 31st December 2017 among residents in Tuscany were collected from the population-based Rare Diseases Registry of Tuscany. All cases were linked to regional health and demographic databases to obtain information about vital statistics, principal causes of hospitalization, complications and comorbidities, and drug prescriptions.

Results: The prevalence of SSc in Tuscany population resulted to be 22.2 per 100,000, with the highest prevalence observed for the cases aged $\geq 65$ years (33.2 per 100,000, CI 95\% 29.6-37.3). In females, SSc was predominant (86.7\% on the total) with an overall sex ratio F/M of 6.5. Nevertheless, males presented a more severe disease, with a lower survival and significant differences in respiratory complications and metabolic comorbidities. Complications and comorbidities such as pulmonary involvement $(H R=1.66, \mathrm{Cl} 95 \% 1.17-2.35)$, congestive heart failure $(\mathrm{HR}=2.76, \mathrm{Cl}$ $95 \%$ 1.80-4.25), subarachnoid and intracerebral haemorrhage ( $\mathrm{HR}=2.33, \mathrm{Cl} 95 \% 1.21-4.48)$ and malignant neoplasms $(H R=1.63, \mathrm{Cl} 95 \%$ 1.06-2.52), were significantly associated to a lower survival, also after adjustment for age, sex and other SSc-related complications. Disease-modifying antirheumatic drugs, endothelin receptor antagonists, and phosphodiesterase- 5 inhibitors were the drugs with the more increasing prevalence of use in the 2008-2017 period.

Conclusions: The multi-database approach is important in the investigation of rare diseases where it is often difficult to provide accurate epidemiological indicators. A population-based registry can be exploited in synergy with health databases, to provide evidence related to disease outcomes and therapies and to assess the burden of disease, relying on a large cohort of cases. Building an integrated archive of data from multiple databases linking a cohort of patients to their comorbidities, clinical outcomes and survival, is important both in terms of treatment and prevention.
\end{abstract}

\footnotetext{
*Correspondence: alessio.coi@ifc.cnr.it

${ }^{\dagger}$ Alessio Coi and Simone Barsotti have equally contributed to this work

${ }^{1}$ Institute of Clinical Physiology, National Research Council, Via Moruzzi 1, Pisa, Italy

Full list of author information is available at the end of the article
} permits use, sharing, adaptation, distribution and reproduction in any medium or format, as long as you give appropriate credit to the original author(s) and the source, provide a link to the Creative Commons licence, and indicate if changes were made. The images or other third party material in this article are included in the article's Creative Commons licence, unless indicated otherwise in a credit line to the material. If material is not included in the article's Creative Commons licence and your intended use is not permitted by statutory regulation or exceeds the permitted use, you will need to obtain permission directly from the copyright holder. To view a copy of this licence, visit http://creativecommons.org/licenses/by/4.0/. The Creative Commons Public Domain Dedication waiver (http://creativeco mmons.org/publicdomain/zero/1.0/) applies to the data made available in this article, unless otherwise stated in a credit line to the data. 
Keywords: Systemic sclerosis, Survival, Mortality risk, Comorbidity, Disease registry, Rare disease,

Pharmacoepidemiology

\section{Background}

Systemic Sclerosis (SSc) is a rare chronic autoimmune disease with a complex pathogenesis that includes vascular injury, abnormal immune activation, and tissue fibrosis [1]. The disease is typically characterized by skin fibrosis, however internal organs may also be frequently affected, in particular kidneys, heart, lungs, and the gastrointestinal tract, thus dramatically reducing the patient's quality of life and survival [2].

Despite the recent advance in the treatment, the prognosis of the patients is still severe and a high percentage of patients mainly dies for pulmonary fibrosis, pulmonary arterial hypertension (PAH) and cardiac disease (mainly heart failure and arrhythmias) [3].

Given the complexity of the study of the epidemiology of SSc, the prevalence in Europe is heterogeneous, ranging from 10 to 35 cases per 100,000 inhabitants [4]. This great difference is mainly due to different timeframes, study designs, data sources (hospitals database, general practitioners, public health data), and classification criteria. Some environmental factors may also influence the prevalence of SSc that appears to be higher in South Europe [5]; furthermore, a geographical variation is observed for several clinical aspects [6].

Most of the published epidemiologic studies on SSc were based on cases collected from records of general practitioners and/or from hospital database [7-16] or from health databases selecting records with the International Classification of Diseases (ICD) code for SSc included in the discharge diagnoses $[17,18]$.

To our knowledge, no studies have been published on SSc based on population-based registries or surveillance registries that, by their nature, are characterized by a high degree of completeness of case ascertainment (external completeness).

Disease registries are considered powerful instruments to develop clinical research in the field of rare diseases (clinical-, hospital-based registries), to improve patient care, and to support healthcare planning through the production of epidemiological indicators based on a specific geographical area (public health-, population-based registries) [19].

Population-based registries often contain information from a large range of conditions, but usually lack of clinical data. This is in contrast with disease-specific registries, that focus on a single disease or on related groups of diseases and have more clinical background [20].
Rare diseases registries, both clinical and populationbased, are an important tool to collect a critical mass of data for epidemiological and/or clinical research, contributing to understand the natural history of rare conditions and to constitute a key information system that supports the activities of the European Reference Networks (ERNs) on rare diseases.

An integrated multi-database, established through the linkage of a population-based registry and data available from health databases routinely collected at geographic level, such as hospital discharge records, prescription database, and vital status database, can be a powerful tool to provide evidence related to disease outcomes and therapies and to assess the burden of disease.

This study is aimed at providing a complete epidemiological profile of SSc in Tuscany (Italy), characterizing the study population in terms of survival, comorbidities and drug prescriptions, by using a multi-database populationbased approach.

\section{Methods}

Cases of SSc diagnosed between 1st January 2003 and 31st December 2017 and residing in Tuscany, an Italian region with a population of 3,744,398 inhabitants, were collected from the population-based Rare Diseases Registry of Tuscany [21]. The registry is based on a regional network allowing the detection of all cases diagnosed at any age, by any of the regional health centres and it is one of the main contributors to the Italian National Registry of Rare Diseases at the Italian National Institute of Health [22].

SSc was diagnosed according to the criteria proposed by the American Rheumatism Association in 1980 [23] and/or the European League Against Rheumatism collaborative initiative/American College of Rheumatology (EULAR/ACR) criteria [24].

All cases endowed of a unique regional anonymous identification number were linked to health and demographic databases of the Tuscany Region to obtain information about vital statistics, hospitalization, complications and drug prescriptions.

Incidence was calculated by 5 -years periods and for the whole study period. Prevalence was calculated at 31st December 2017 (population of Tuscany: 3,736,968 inhabitants); information about deaths and migrations necessary to produce prevalence estimates were gained from regional health and demographic databases (mortality database, Registry Office, hospital 
discharges database). Population stratified by sex and age was extracted by the National Institute of Statistics.

A Poisson regression model was used for testing differences in prevalence among age classes $(<25,25-44$, $45-64, \geq 65)$. Mean age at diagnosis was expressed in years \pm standard deviation.

The most frequent SSc-related complications and comorbidities were investigated according to the recent literature $[25,26]$ and were defined using the hospital discharge database with the International Classification of Diseases, Ninth Revision, Clinical Modification (ICD-9-CM) diagnosis codes (see Additional file 1: Table S1).

Principal causes of hospitalization (calculated on the total of inpatient cases), Length of Stay (LOS), i.e. the number of nights the patient remained in the hospital, and average LOS were also provided. Sex differences in SSc-related complications/comorbidities and principal causes of hospitalization were tested using the test for the difference between proportions.

Survival for SSc-cases was defined with the first registration of diagnosis and censored at death or at 1, 3, 5 , and 10 years follow-up, using the Kaplan-Meier method and survival curves were compared using the log-rank test. The analysis of the effect of SSc-related complications and comorbidities on survival, adjusted by age and sex, were performed using Cox proportional hazards regression.

Drug prescriptions database, containing information on dispensed drugs reimbursed by the National Health Service, was available for this study from 1st January 2008. Only outpatient prescriptions were collected in the database. The prevalence of use of the most common classes of prescribed drugs in SSc (see Additional file 1: Table S2) was calculated for each year of the 2008-2017 period, by dividing the number of SSc cases with at least one dispensing of each pharmaceutical class for the number of prevalent cases at the beginning of each year. Defined Daily Dose (DDD) per 1000 cases per day (DDD/1000 cases/day), was used as an estimate of the proportion of the study population daily treated with a particular drug or group of drugs: 10 DDDs per 1000 cases per day means that in a representative group of 1000 SSc cases, 10 DDDs of the drug are utilized on average, on any given day of the year analysed. Investigated drugs were selected according to EULAR and EUSTAR (EULAR Scleroderma Trials and Research group) recommendations and updates for the treatment of SSc and to literature [27-29]. The Anatomical Therapeutic Chemical (ATC) classification system was used to code drugs information.
The data were analysed with STATA, version 16 [30]. Two-sided $p$-value $<0.05$ was considered statistically significant in all analyses of this study.

Prior to their insert in the Rare Diseases Registry of Tuscany, an informative note, specifying that data can be used for research purpose, is delivered to each patient.

\section{Results}

A total of 924 cases of SSc (801 females and 123 males) were diagnosed during the 2003-2017 period. Distribution of cases by 10-years age-classes was as follows: $0-17: \mathrm{n}=2 ; 18-24: \mathrm{n}=10 ; 25-34: \mathrm{n}=50 ; 35-44: \mathrm{n}=106$; 45-54: $\mathrm{n}=163 ; 55-64: \mathrm{n}=215 ; 65-74: \mathrm{n}=240 ; 75-84:$ $\mathrm{n}=130 ; 85+: 8$. SSc was predominant in females $(801$ out of 924 cases, $86.7 \%$ of the total) with an overall sex ratio $\mathrm{F} / \mathrm{M}$ of 6.5 .

The prevalence, estimated at 31st December 2017, was 22.2 per 100,000 (Confidence Interval 95\%, CI 95\% 20.7-23.8), with significantly statistical differences among age classes $(p<0.0001)$. In particular, a decreasing prevalence was observed across age classes according to the following order: $\geq 65$ years $(33.2$ per $100,000, C I$ 95\% 29.6-37.3), 45-64 (31.3, CI 95\% 28.1-34.8), 25-44 (17.5, CI 95\% 14.8-20.5), <25 (1.5, CI 95\% 0.8-2.6). Male and female prevalence estimates were 5.9 and 37.5 per 100,000 , respectively.

The overall incidence for the 2003-2017 period was 1.7 per 100,000 (0.5 and 2.8 per 100,000 for males and females, respectively). Incidence across the 5 -year periods 2003-2007, 2008-2012, and 2013-2017 did not differ significantly $(p=0.56)$, ranging from 1.5 to 1.8 per 100,000 .

The overall mean age at diagnosis was $59.4 \pm 14.6$, without significant differences $(p=0.61)$ among males and females ( $58.8 \pm 15.1$ and $59.5 \pm 14.6$, respectively).

\section{Hospitalization}

The linkage between the study population and the hospital discharge database was possible for 899 out of 924 cases of SSc $(97.3 \%) ; 76.5 \%(n=688)$ of the investigated cohort had at least one admission in the study period. Hospitalization was significantly higher in males than in females ( $p<0.01 ; 86.8$ and $74.9 \%$, respectively).

A total of 4111 admissions and a total LOS of 28,921 days with a mean length of inpatient stay of 7.0 days were observed, without detecting statistically significant differences between males and females (7.3 and 7.0, respectively). The average number of hospital admissions for each case was equal to 6 (6.3 for males, 5.9 for females).

Cardiovascular (40.8\%) and pulmonary (36.2\%) diseases constituted the majority of SSc complications (Table 1). Among these two disease groups, chronic ulcer 
of skin (20.4\%) and lung involvement (28.1\%) were the most frequent diseases.

Malignant neoplasms of bone, connective tissue, skin, and breast $(30.5 \%)$, genitourinary organs (17.8\%), respiratory and thoracic organs (16.9\%), and digestive and peritoneum (15.3\%) were the most frequent among the 118 cases of tumours observed in our study.

Males were more represented than females for respiratory diseases such as pulmonary fibrosis ( $8.3 \%$ vs $4.0 \%$, $p=0.04)$ and pneumonia ( $13.2 \%$ vs $5.7 \%, p=0.002)$, for diabetes mellitus $(15.7 \%$ vs $9.6 \%, p=0.04)$, and for gout (26.4\% vs $12.6 \%, p=0.0001)$.

Among the main causes of hospitalization, diseases of the circulatory and respiratory systems were the most frequent, with percentages of $35.2 \%$ and $22.1 \%$, respectively, calculated on the total inpatient cases (Table 2).

Significant sex differences $(p<0.05)$ were observed for diseases of the circulatory system, with higher hospitalization among males (43.8\%) than females (33.6\%), and for diseases of the respiratory system, with a percentage of $26.5 \%$ for males and $21.3 \%$ for females. In particular, within the respiratory group, males resulted to be hospitalized at a significantly higher percentage than females for interstitial lung diseases (ICD9-CM: 515-517, 9.5\% vs $4.6 \%, p=0.01$ ).

\section{Survival}

During the study period, 132 patients died (22 males and 110 females). The average age at death was 74.0 years (range: 42-97 years); 72.4 and 74.3 years for males and females, respectively.

Overall survival rates at $1,3,5$, and 10 years from diagnosis were $98.4 \%, 95.7 \%, 91.6 \%$, and $79.4 \%$, respectively.

The Kaplan-Meier survival analysis and the long-rank test demonstrated a higher survival in females than in males, even if borderline significant $(p=0.06)$ (Fig. 1); the survival rates at 5 year were $85.6 \%$ of males and $92.4 \%$ of females, respectively. The survival at 5 years for age classes $45-64$ and $65+$ years was $96.4 \%$ and $82.8 \%$, respectively. No deaths were observed for cases under 45 years-old.

The Hazard Ratio (HR) for females was 0.65 , borderline significant (CI 95\% 0.41-1.03) after adjustment for age at diagnosis. HR significantly increased with age at diagnosis, resulting to be 1.09 (CI 95\% 1.07-1.11) for each year increase, also after adjustment for sex.

Table 3 reported HRs related to the main investigated complications adjusted for sex and age at diagnosis.

Among the cardiovascular disorders, subarachnoid and intracerebral haemorrhage, congestive heart failure, and gangrene were associated with a lower survival. A higher risk of mortality was also associated to pulmonary fibrosis, lung involvement and $\mathrm{PAH}$, among the pulmonary
Table 1 SSc-related complications and comorbidities in inpatient population in the 2003-2017 period: number of cases and percentages by sex, referred to the inpatient population and test to assess statistically significant sex differences

\begin{tabular}{|c|c|c|c|c|}
\hline & & Cases & $\%$ & pr-test \\
\hline \multirow[t]{3}{*}{ Heart and Circulation ${ }^{a}$} & M & 55 & 45.5 & 0.26 \\
\hline & $\mathrm{F}$ & 312 & 40.1 & \\
\hline & Total & 367 & 40.8 & \\
\hline \multirow[t]{3}{*}{ Acute myocardial infarction } & M & 5 & 4.1 & 0.18 \\
\hline & $\mathrm{F}$ & 16 & 2.1 & \\
\hline & Total & 21 & 2.3 & \\
\hline \multirow{3}{*}{$\begin{array}{l}\text { Subarachnoid and intracerebral haemor- } \\
\text { rhage }\end{array}$} & M & 1 & 0.8 & 0.83 \\
\hline & $\mathrm{F}$ & 8 & 1.0 & \\
\hline & Total & 9 & 1.0 & \\
\hline \multirow[t]{3}{*}{ Ischemic stroke events } & M & 2 & 1.7 & 0.72 \\
\hline & $\mathrm{F}$ & 10 & 1.3 & \\
\hline & Total & 12 & 1.3 & \\
\hline \multirow[t]{3}{*}{ Congestive heart failure } & M & 16 & 13.2 & 0.46 \\
\hline & $\mathrm{F}$ & 85 & 10.9 & \\
\hline & Total & 101 & 11.2 & \\
\hline \multirow[t]{3}{*}{ Malignant essential hypertension } & M & 0 & 0.0 & 0.23 \\
\hline & $\mathrm{F}$ & 9 & 1.2 & \\
\hline & Total & 9 & 1.0 & \\
\hline \multirow[t]{3}{*}{ Gangrene } & M & 2 & 1.7 & 0.48 \\
\hline & $\mathrm{F}$ & 22 & 2.8 & \\
\hline & Total & 24 & 2.7 & \\
\hline \multirow{3}{*}{$\begin{array}{l}\text { Chronic ulcer of skin (except pressure } \\
\text { ulcer) }\end{array}$} & M & 28 & 23.1 & 0.42 \\
\hline & $\mathrm{F}$ & 155 & 19.9 & \\
\hline & Total & 183 & 20.4 & \\
\hline \multirow[t]{3}{*}{ Lung $^{b}$} & M & 53 & 43.8 & 0.06 \\
\hline & $\mathrm{F}$ & 272 & 35.0 & \\
\hline & Total & 325 & 36.2 & \\
\hline \multirow[t]{3}{*}{$\mathrm{PAH}$} & M & 5 & 4.1 & 0.33 \\
\hline & $\mathrm{F}$ & 50 & 6.4 & \\
\hline & Total & 55 & 6.1 & \\
\hline \multirow[t]{3}{*}{ Lung involvement } & M & 38 & 31.4 & 0.39 \\
\hline & $\mathrm{F}$ & 215 & 27.6 & \\
\hline & Total & 253 & 28.1 & \\
\hline \multirow[t]{3}{*}{ Pulmonary fibrosis } & M & 10 & 8.3 & 0.04 \\
\hline & $\mathrm{F}$ & 31 & 4.0 & \\
\hline & Total & 41 & 4.6 & \\
\hline \multirow[t]{3}{*}{ Pneumonia } & M & 16 & 13.2 & 0.002 \\
\hline & $\mathrm{F}$ & 44 & 5.7 & \\
\hline & Total & 60 & 6.7 & \\
\hline \multirow[t]{3}{*}{ Pulmonary embolism } & M & 0 & 0.0 & - \\
\hline & $\mathrm{F}$ & 13 & 1.7 & \\
\hline & Total & 13 & 1.4 & \\
\hline \multirow[t]{3}{*}{ Kidneyc } & M & 5 & 4.1 & 0.91 \\
\hline & $\mathrm{F}$ & 34 & 4.4 & \\
\hline & Total & 39 & 4.3 & \\
\hline
\end{tabular}


Table 1 (continued)

\begin{tabular}{|c|c|c|c|c|}
\hline & & Cases & $\%$ & pr-test \\
\hline \multirow[t]{3}{*}{ Chronic kidney disease } & M & 1 & 0.83 & 0.48 \\
\hline & $\mathrm{F}$ & 13 & 1.67 & \\
\hline & Total & 14 & 1.56 & \\
\hline \multirow[t]{3}{*}{ Acute renal failure } & M & 4 & 3.3 & 0.95 \\
\hline & $\mathrm{F}$ & 25 & 3.2 & \\
\hline & Total & 29 & 3.2 & \\
\hline \multirow[t]{3}{*}{ Gastrointestinal tract $^{d}$} & M & 5 & 4.1 & 0.56 \\
\hline & $\mathrm{F}$ & 24 & 3.1 & \\
\hline & Total & 29 & 3.2 & \\
\hline \multirow[t]{3}{*}{ Hemorrhage of gastrointestinal tract } & M & 0 & 0.0 & - \\
\hline & $\mathrm{F}$ & 4 & 0.5 & \\
\hline & Total & 4 & 0.4 & \\
\hline \multirow[t]{3}{*}{ Intestinal obstruction (without hernia) } & M & 5 & 4.1 & 0.39 \\
\hline & $\mathrm{F}$ & 21 & 2.7 & \\
\hline & Total & 26 & 2.9 & \\
\hline \multirow[t]{3}{*}{ Metabolism ${ }^{\mathrm{e}}$} & M & 43 & 35.5 & 0.0001 \\
\hline & $F$ & 153 & 19.7 & \\
\hline & Total & 196 & 21.8 & \\
\hline \multirow[t]{3}{*}{ Diabetes mellitus } & M & 19 & 15.7 & 0.04 \\
\hline & $\mathrm{F}$ & 75 & 9.6 & \\
\hline & Total & 94 & 10.5 & \\
\hline \multirow[t]{3}{*}{ Gout } & M & 32 & 26.4 & 0.0001 \\
\hline & $\mathrm{F}$ & 98 & 12.6 & \\
\hline & Total & 130 & 14.5 & \\
\hline \multirow[t]{3}{*}{ Malignant neoplasms } & M & 18 & 14.9 & 0.55 \\
\hline & $\mathrm{F}$ & 100 & 12.9 & \\
\hline & Total & 118 & 13.1 & \\
\hline
\end{tabular}

$\%$, percentages referred to the total of the inpatient population; pr-test, $p$-value of the test of difference of proportion, a $p$-value $<0.05$ (in bold) indicates a statistically significant difference in SSc-related complications between males and females

${ }^{a}$ Cases with at least one occurrence of the following complications or comorbidities: acute myocardial infarction, subarachnoid and intracerebral haemorrhage, ischemic stroke events, congestive heart failure, malignant essential hypertension, gangrene, and chronic ulcer of skin

b Cases with at least one occurrence of the following complications or comorbidities: PAH, lung involvement in systemic sclerosis, pneumonia, and pulmonary embolism

c Cases with at least one occurrence of the following complications or comorbidities: chronic kidney disease and acute renal failure

d Cases with at least one occurrence of the following complications or comorbidities: haemorrhage of gastrointestinal tract and intestinal obstruction

e Cases with at least one occurrence of the following complications or comorbidities: diabetes mellitus and gout

complications, and to acute renal failure, intestinal obstruction, and malignant neoplasms.

In order to evaluate the net effect of SSc-related complications and comorbidities on survival, a Cox regression model including all complications was developed. Congestive heart failure ( $\mathrm{HR}=2.76$, CI 95\% 1.80-4.25), subarachnoid and intracerebral haemorrhage $(\mathrm{HR}=2.33$,
CI 95\%1.21-4.48), pulmonary involvement (lung involvement and pulmonary fibrosis, and $\mathrm{PAH})(\mathrm{HR}=1.66, \mathrm{CI}$ $95 \% 1.17-2.35)$, and malignant neoplasms $(\mathrm{HR}=1.63$, CI 95\% 1.06-2.52), were confirmed to be significantly associated to a lower survival also after adjustment for all other complications. Renal involvement (chronic kidney disease and acute renal failure) $(\mathrm{HR}=1.66, \mathrm{CI} 95 \%$ 0.99-2.79) and gangrene ( $\mathrm{HR}=1.73, \mathrm{CI} 95 \% 0.93-3.20)$ resulted to be borderline significant.

\section{Pharmacoepidemiology}

Looking at the prevalence of use of the investigated drug classes, disease-modifying antirheumatic drugsDMARDs (azathioprine, cyclophosphamide, ciclosporin, methotrexate, hydroxychloroquine, mycophenolic acid, rituximab) showed the higher percentage of users in the last years (43\%), characterized by a continuous increasing trend since 2008 (Fig. 2).

Glucocorticoids (prednisone and methylprednisolone) showed an increasing prevalence from 2008 (31.9\%) to 2013 (41.1\%), followed by a rather steady trend in the last four years (2014-2017).

Among the DMARDs, hydroxychloroquine had the highest number of users: in 2017 more than 1 out of 4 cases $(26.3 \%)$ had at least one prescription of this drug (Fig. 3). An increasing trend was also observed for mycophenolic acid, whose prevalence increased from 0.8 to $11.1 \%$ in the $2008-2017$ period. Rituximab also showed an increasing trend, but with lower percentages of users, with a maximum of $4.7 \%$ in 2017 . A steady trend of the percentage of users of methotrexate was observed from 2012 to 2017 (ranging from a minimum of $6.5 \%$ in 2012 to a maximum of $7.4 \%$ in 2013), with an increase observed from 2008 (3.5\%) to 2012 (6.5\%). Azathioprine and ciclosporin showed decreasing trends, the former was almost halved from 2008 (3.9\%) to 2017 (2.3\%), the latter decreased from $1.6 \%$ in 2008 to $0.4 \%$ in 2017. Cyclophosphamide showed a very low prevalence of use, with a maximum of $1.5 \%$ observed in 2017.

Phosphodiesterase-5 (PDE-5) inhibitors (tadalafil, vardenafil, and sildenafil) and Endothelin Receptor Antagonists (ERA) (bosentan, ambrisentan, and macitentan), both recommended for $\mathrm{PAH}$ and digital ulcers, had a similar trend in the 2010-2017 period. The increase was more pronounced in PDE-5 inhibitors (varying from 3.9 to $22.9 \%$ ) than in ERA (varying from 16.5 to $25.5 \%$ ).

ACE inhibitors and Angiotensin II Receptor Blockers (ARB) (considered as plain and in association with dihydropyridine derivatives) showed a steady trend in the period under investigation ranging from a minimum of $24.4 \%$ (in 2008) and a maximum of $26.6 \%$ (in 2013). 
Table 2 Causes of hospitalization among inpatient cases of SSC

\begin{tabular}{llll}
\hline Cause of hospitalization & ICD9-CM & Frequency & \% \\
\hline Diseases of the circulatory system & $390-459$ & 242 & 35.2 \\
Diseases of the respiratory system & $460-519$ & 152 & 22.1 \\
Diseases of the digestive system & $520-579$ & 124 & 18.0 \\
Diseases of the skin and subcutaneous tissue & $680-709$ & 83 & 12.1 \\
Malignant neoplasms & $140-209,230-239$ & 79 & 11.5 \\
\hline
\end{tabular}

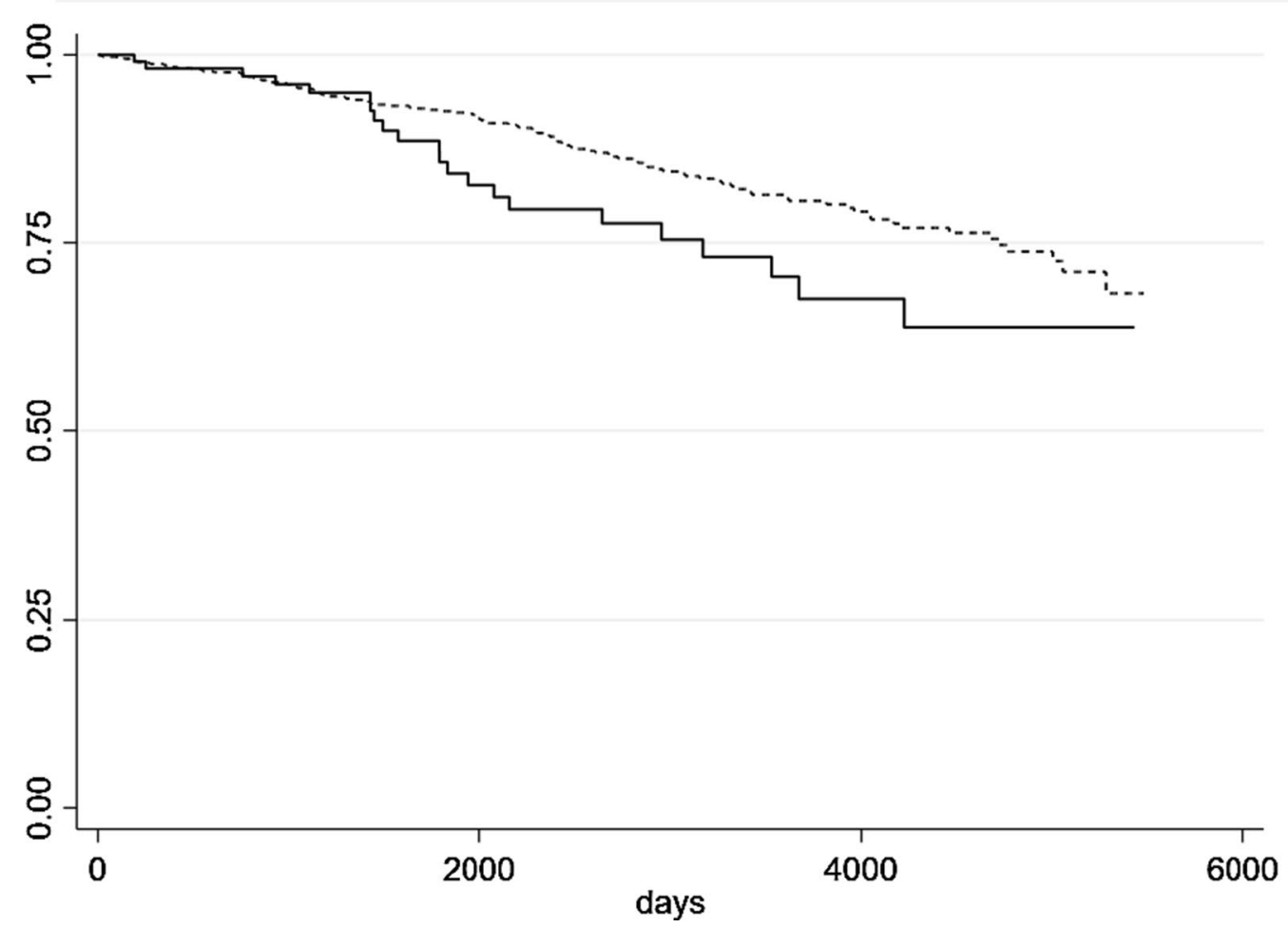

Fig. 1 Kaplan-Meier survival curves by sex (males and females in continue and dotted lines, respectively)

The calcium channel blockers (CCB) dihydropyridine derivatives were the only ones characterized by a decreasing trend from 32.7 to $28.2 \%$, with a higher percentage of users (34\%) observed in the 2013-2014 period.

Prostanoids (prostacyclin analogues: iloprost, epoprostenol, treprostinil) showed an increasing trend from 2011 (5.3\%) to 2017 (13.7\%); among them, iloprost was the most used.

Looking at the intensity of use, expressed as defined daily dose (DDD) per 1000 cases per day, ACE inhibitors and ARB, DMARDs, PDE-5 inhibitors and ERA showed a steady increasing trend from 2008 to 2017 reaching a maximum of 539.2, 269.1, 160.8 and 159.0 $\mathrm{DDD} / 1000$ cases/day, respectively.
For $\mathrm{CCB}$ dihydropyridine derivatives a steady trend in use was observed along the investigated period, ranging from a minimum of $328.6 \mathrm{DDD} / 1000$ cases/day in 2012 to a maximum of 377.7 in 2017.

Glucocorticoids methylprednisolone and prednisone were the only ones with a decreasing trend varying from 248.4 DDD/1000 cases/day in 2008 to 215.8 in 2017.

Among the DMARDs, hydroxychloroquine was the most used with a pronounced increasing trend from 2008 (74.8 DDD/1000 cases/day) to 2017 (150.7 DDD/1000 cases/day).

Other drugs or classes of drugs were also investigated. Proton-pump inhibitors, that should be used for the treatment of SSc-related gastro-esophageal reflux diseases (GERD) (strength of recommendation B according 
Table 3 Hazard ratio between SSc-related complications and comorbidities and survival (statistically significant associations are reported in bold)

\begin{tabular}{lll}
\hline SSc-related complications and comorbidities & HR $^{\mathbf{a}}$ & $\mathbf{C l} \mathbf{9 5 \%}$ \\
\hline Acute myocardial infarction & 2.14 & $0.93-4.89$ \\
Subarachnoid and intracerebral haemorrhage & $\mathbf{2 . 2 6}$ & $1.32-3.87$ \\
Ischemic stroke events & 1.30 & $0.24-3.63$ \\
Congestive heart failure & $\mathbf{3 . 5 4}$ & $2.38-5.28$ \\
Malignant essential hypertension & 3.68 & $0.97-14.0$ \\
Gangrene & $\mathbf{2 . 3 0}$ & $1.27-4.14$ \\
Chronic ulcer of skin (except pressure ulcer) & 1.36 & $0.95-1.95$ \\
PAH & $\mathbf{2 . 2 4}$ & $1.41-3.55$ \\
Lung involvement & $\mathbf{1 . 5 0}$ & $1.06-2.11$ \\
Pulmonary fibrosis & $\mathbf{2 . 6 0}$ & $1.56-4.35$ \\
Pneumonia & 1.59 & $1.00-2.53$ \\
Pulmonary embolism & 1.55 & $0.55-4.35$ \\
Chronic kidney disease & 1.30 & $0.58-2.88$ \\
Acute renal failure & $\mathbf{2 . 7 4}$ & $1.62-4.63$ \\
Haemorrhage of gastrointestinal tract & 2.69 & $0.73-9.93$ \\
Intestinal obstruction (without hernia) & $\mathbf{3 . 3 9}$ & $2.03-5.66$ \\
Diabetes mellitus & 1.31 & $0.84-2.04$ \\
Gout & 1.35 & $0.94-1.95$ \\
Malignant neoplasm & $\mathbf{1 . 8 8}$ & $1.27-2.80$ \\
\hline
\end{tabular}

$\mathrm{HR}$, hazard ratio; $\mathrm{C} 195 \%$, confidence interval

${ }^{\text {a }}$ HRs are adjusted for sex and age at diagnosis

to EULAR) [28], show a steady trend for prevalence of use, ranging from 69 and $72 \%$.

Riociguat, a stimulator of soluble guanylate cyclase (sGC) that has been recently approved for the treatment of PAH, showed no prescriptions before 2017.

Among the innovative therapies, in the last years the prescription of tocilizumab, an interleukin 6 inhibitor, and high dosage of polyclonal intravenous immunoglobulins (IvIg) has started in patients with SSc. Indeed, although the numbers of patients treated with tocilizumab were limited ( 1 case in 2014 and 3 cases each year in the 2015-2017 period), the prescription of IvIg showed a more rapid increase, ranging from 1 case in 2010 (prevalence 0.3\%) up to 18 cases in 2017 (2.4\% of the investigated sample).

\section{Discussion}

The study provides a whole epidemiological profile for SSc, underlining the importance of integrating cases of a rare disease collected by a population-based registry through a multi-database approach, in order to characterize the disease in terms of survival, comorbidities and drug prescriptions.

The sex ratio, together with the observed differences of both prevalence and incidence estimates between males and females, could lead to hypothesize clinically important sex differences. Literature data suggest that the difference is even more pronounced during the reproductive period, and the increased expression of inflammatory mediators during pregnancy may play a role in this aspect [31]. However, looking at the complications, survival, and survival adjusted for risk factors, our results showed that there is a different clinical pattern according to sex in patients with SSc. Males presented a more severe disease than females resulting in a lower survival at 5 years, with evident and significant differences in respiratory complications and metabolic comorbidities. Our results suggest that males should be monitored since the early stage of the disease, in order to: (1) detect systemic involvement even in the absence of other clinical symptoms; (2) identify the best therapeutic strategy to prevent negative clinical outcomes and improve the prognosis.

The prevalence calculated in our study (22.2 per $100,000)$ was in agreement with estimates observed by a recent systematic review on SSc by Bergamasco et al. reporting highly heterogeneous prevalence estimates across 11 studies performed in Europe, ranging from 7.2 to 33.9 per 100,000 individuals [32]. Discrepancies among studies of SSc prevalence are mainly due to different case classification and different methods of retrieval of cases (registries, hospitals, or general practitioners, individually or in multi-source approach).

The incidence of 1.7 per 100,000 for the 2003-2017 period observed in our study, with a difference between males and females ( 0.5 and 2.8 per 100,000 , respectively), was consistent with the estimates of annual incidence of five European studies (ranging from 0.6 to 2.3), who also reported a higher incidence in females than in males $(1.8$ vs 0.7 per 100,000) [32].

The study population, with an observed overall mean age at diagnosis of 59.4, appeared to be similar to those reported by Bergamasco et al., ranging from 50.2 to 59.8 (only age at diagnosis considered). We have not observed significant differences in age at diagnosis between males and females, in contrast with Alamanos et al. who found women to have a lower mean age compared to men (49.2 \pm 15.7 and $58.9 \pm 13.5$ years, respectively) [7].

\section{Hospitalization}

Concerning the cardiovascular complications and comorbidities, proportion observed in our study for myocardial infarction (2.3\%) and ischemic stroke events (1.3\%) are consistent with what reported by Butt et al. (3\% for both comorbidities) [18], Man et al. (2.3\% for myocardial infarction and $2.5 \%$ for ischemic stroke events) [10], and Chu et al. (2.3\% for myocardial infarction) [33]. Our estimates are slightly lower respect to what reported by Aviña-Zubieta et al. (4.7\% and 2.9\%) [34], but in this case, 


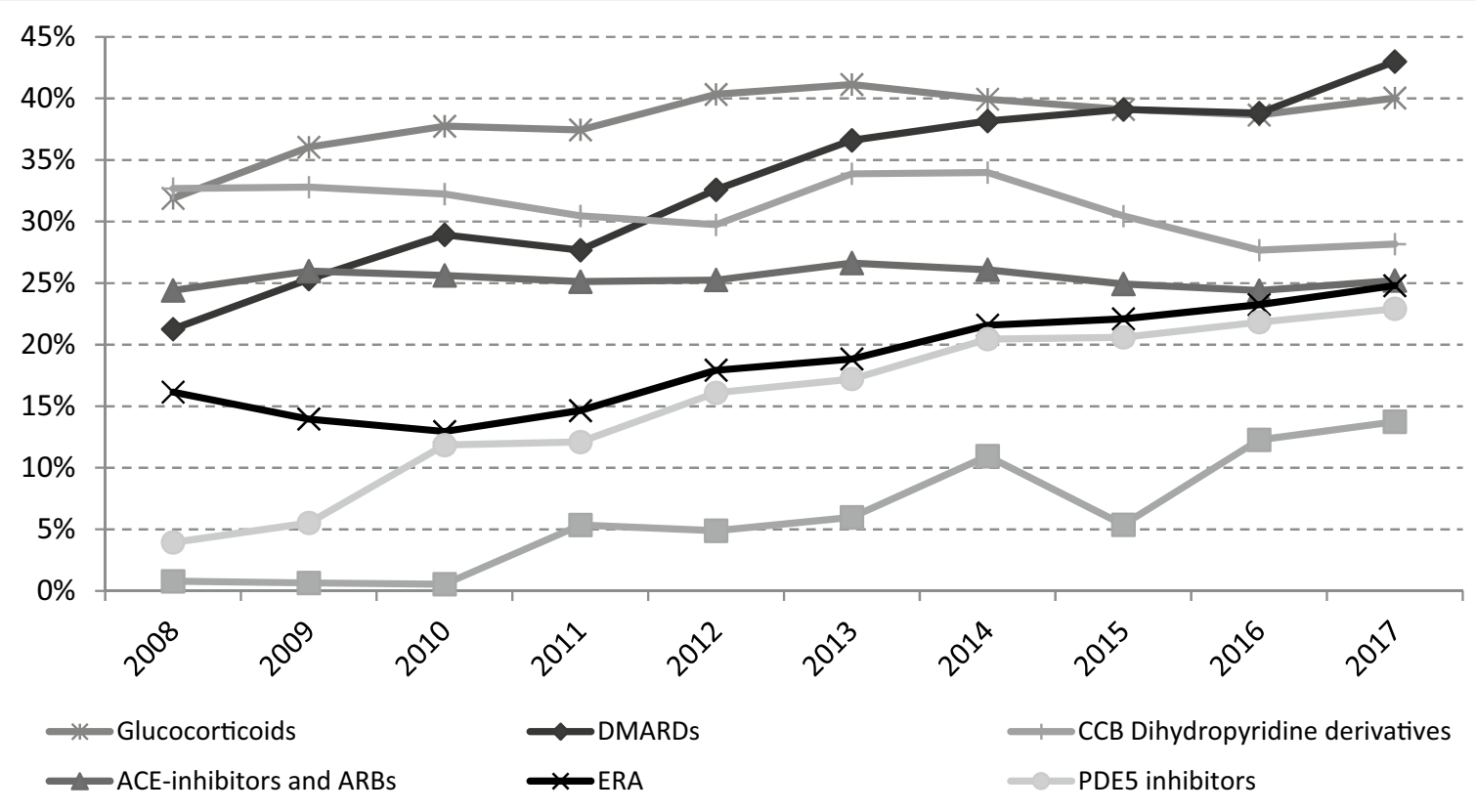

Fig. 2 Prevalence trend (2008-2017) of the investigated drug classes. Glucocorticoids: methylprednisolone and prednisone; Disease-modifying antirheumatic drugs (DMARDs): azathioprine, cyclophosphamide, ciclosporin, methotrexate, hydroxychloroquine, mycophenolic acid, and rituximab; Calcium Channel Blockers (CCB) dihydropyridine derivatives; ACE inhibitors and ARBs (Angiotensin II Receptor Blockers) (plain and in association with dihydropyridine derivatives); Endothelin Receptor Antagonists (ERA): bosentan, ambrisentan, and macitentan; PDE-5 inhibitors (phosphodiesterase-5 inhibitors): tadalafil, vardenafil, and sildenafil; Prostanoids (prostacyclin analogues): iloprost, epoprostenol, treprostinil

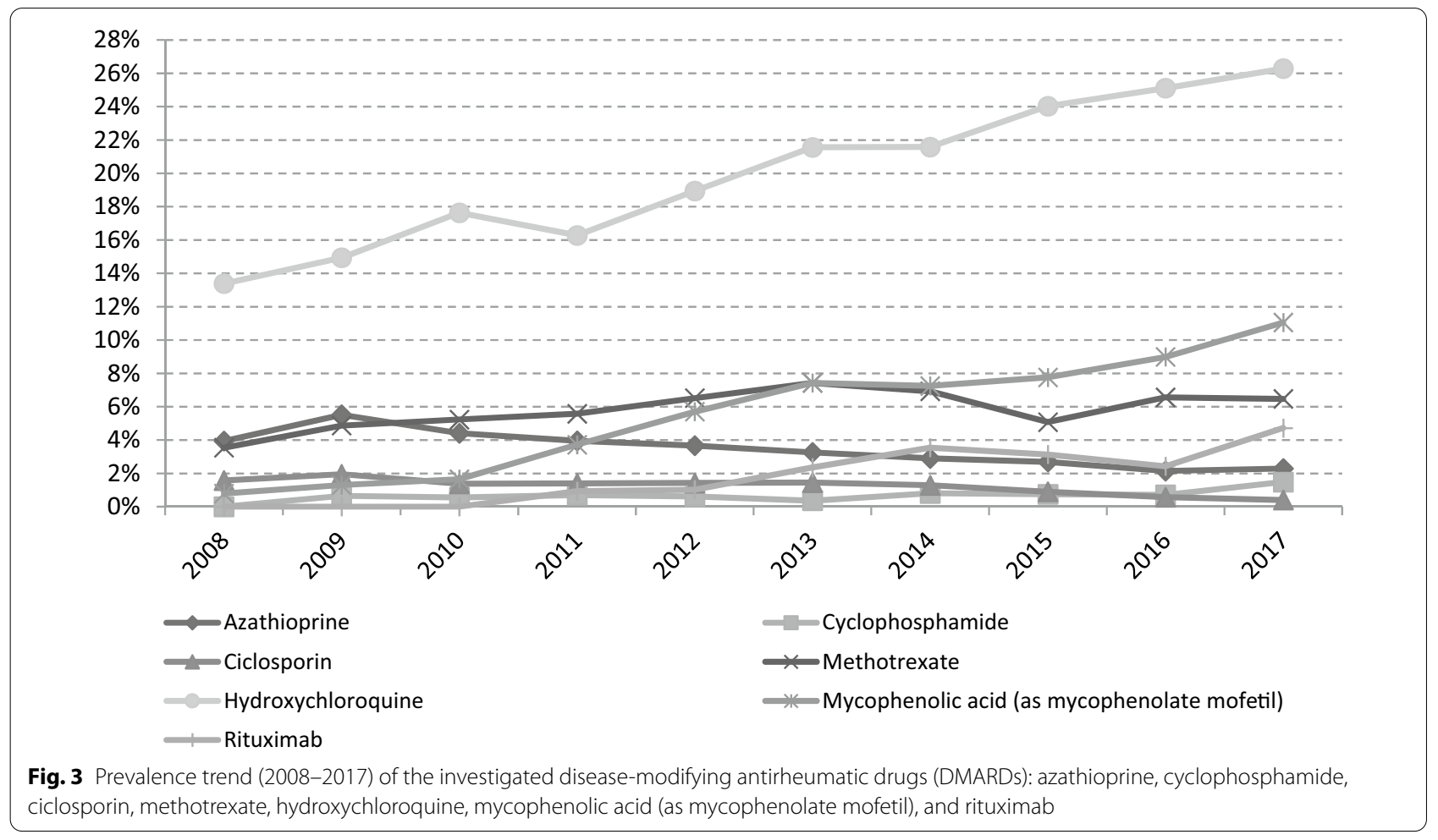


the Authors declared that their study showed a higher risk of both myocardial infarction and stroke in comparison to previous studies, maybe because they utilized both hospitalization data and death certificate codes. Percentage of congestive heart failure observed in our study $(11.2 \%)$ are in the wide range of values observed by Butt et al. (3\%) [18] and Amoda et al. (24.4\%) [17]. This heterogeneity mainly depends on different definitions of both SSc cases and heart failure.

We observed $2.7 \%$ of cases with gangrene which is not directly comparable to a few studies reporting $1.7 \%$, $3.9 \%$ and $5 \%$ of cases with peripheral artery disease $[10$, $18,33]$. However, the sum of cases of chronic ulcer of skin (20.4\%) and gangrene (2.7\%) observed in our cohort is consistent with the findings of Noviani et al. who reported $24.3 \%$ of cases with digital ulcers or gangrene [15].

Concerning the pulmonary complications, we observed a prevalence of PAH of $6.1 \%$, which is consistent with literature data, reporting heterogeneous estimates ranging between 4.9 and $26.7 \%$ depending on the applied diagnostic tools and definitions [35].

We found $31.2 \%$ of total pulmonary involvement $(28.1 \%$ of cases with lung involvement and 3.1\% with pulmonary fibrosis as defined with ICD-9-CM). Our results are not directly comparable to other studies, as we defined lung involvement according to ICD-9-CM codes and we do not have data on the prevalence of pulmonary fibrosis alone based on high-resolution computerized tomography of the lungs.

Concerning the renal complications, our prevalence of $4.3 \%$ was slightly higher than the proportion reported in a hospital-based study developed in Northwestern Spain (1\% of SSc-related renal crisis) [9]. This difference could be explained by the inclusion of non-SSc-related renal failure in our prevalence estimate of $4.3 \%$, since in our database we were not able to identify specific SSc-related renal failure.

Concerning the metabolic comorbidities, percentage of diabetes mellitus among our inpatient population, $(10.5 \%)$ was consistent with what observed by Amoda et al. (11.4\% for the sum of diabetes with and without other associated complications) [17] and by Chu et al. (12.1\%) [33].

Concerning the malignant neoplasms, the observed percentage of $13.1 \%$ was slightly higher but consistent with what reported in literature. In particular, Pagkopoulou et al. reported in a recent review that malignancies in patients with SSc occur in a percentage of 3.6-10.7\%, but with varying incidence estimates among studies reflecting the heterogeneity of SSc as well as the epidemiologic variations of the disease across different countries [36].

\section{Survival and risk factors}

Our results for survival at 5 and 10 years $(91.6 \%$ and $79.4 \%$, respectively) were higher than those reported by Bergamasco et al., who identified three publications reporting survival rates in the ranges of $83-84 \%$ and $65-73 \%$ at 5 and 10 years, respectively [7, 9, 32, 37]. This discrepancy can have a reason in the fact that these studies have been developed on data referred to preceding decades (1988-2006, 1981-2002, and 1983-2005) and suggests that the survival of SSc patients may have improved over the last decade. This hypothesis is plausible, taking into account the improvement occurred in the last years in terms of early diagnosis and consequently of treatment, not only of SSc as a whole, but also of its complications and comorbidities that may have a negative impact on patients' survival.

Confirming results come from Butt et al. who recently investigated the mortality-rates of SSc in the 1995-2015 period, observing the 1-year all-cause mortality rate per 100 person-years decreasing from 6.1 in 1995 to 5.3 in 2015 [18].

Regarding the effect of SSc-related complications and comorbidities on survival, our results were consistent with what was recently reported in a meta-analysis by Pokeerbux et al., who observed that age at diagnosis, male sex, renal involvement and SSc-related renal crisis, interstitial lung disease, cardiac involvement, and cancer were significantly associated with a worse prognosis [16].

In our study, both congestive heart failure and renal involvement were associated to poor prognosis (lower survival). More than half of the cases (20 out of 39) with renal involvement (chronic kidney disease or acute renal failure) also presented congestive heart failure, thus suggesting that heart failure may cause renal failure, probably due to the cortical renal hypoperfusion, as hypothesized by other Authors [38].

We observed that intestinal occlusion was associated to a lower survival. Very few studies investigated this association; Mecoli et al. evidenced a higher mortality in SSc patients with acute intestinal pseudo-obstruction who had low haemoglobin and serum albumin levels at presentation [39].

\section{Pharmacoepidemiology}

The analysis on drug prescriptions allows identifying an increase of use for different categories of drugs. Being SSc a complex disease, the therapeutic approach includes several immuno-active and vasoactive drugs.

Concerning the immune-active drugs, glucocorticoids, although associated with a higher risk of scleroderma renal crisis [28], are frequently prescribed as they are part of the therapeutic strategy in the management of 
inflammatory arthritis. Recent evidences suggest that using glucocorticoids at a low-dosage is relatively safe [40] and may be helpful in patients with SSc, in particular in those with an early disease characterized by a prevalent inflammation [41]. This is in line with what observed in our study since methylprednisolone and prednisone were the only drugs with a decreasing trend in term of intensity of use along the 2008-2017 period. As reported in literature, a long-term use or high doses of glucocorticoids is associated with numerous side effects such as hyperglycaemia or diabetes [42]. Despite this, we did not observe in our cohort an increase of diabetes following the therapy with glucocorticoids, probably due to the low dosage usually prescribed in SSc. In particular, we observed 43 cases with diabetes out of 584 cases treated with glucocorticoids (6.9\%) and 9 cases with diabetes out of 207 cases not treated with glucocorticoids (4.2\%). Despite the higher percentage, the difference between these proportions was not statistically significant $(p=0.156)$.

As glucocorticoid use may be insufficient and burdened by adverse events, the use of DMARDs is often proposed. Immunosuppressants may allow a better disease control and their use is also recommended in the most recent EULAR guidelines for treatment of SSc [28]. In our cohort, the results confirmed a significant increased prevalence and intensity of use of immunosuppressants during the study period. In particular, there was an increase of the use of mycophenolate mofetil and cyclophosphamide (even if with a lower prevalence) and this is probably due to the recognized effectiveness of these two treatments for interstitial lung disease, pulmonary fibrosis, skin and cardiac involvement [43, 44]. On the contrary, the prevalence of use of azathioprine and cyclosporine-A decreased, in the latter case it is probably due the possible association with the scleroderma renal crisis [45].

Methotrexate has been recommended by EULAR (strength A) for the treatment of skin manifestations of early diffuse SSc [28] and, similarly to what reported by Panoupulos et al. [46], it has been the most prescribed immunosuppressant for this condition until 2014, when it was overcome by mycophenolate mofetil, as also observed in our study.

Hydroxychloroquine is the most used DMARD and the percentage of treated patients showed a constant increasing trend, likely for beneficial impact on joint involvement, as recently observed [47].

The use of rituximab, a B-cell depleting monoclonal antibody, increased in the last years for the treatment of skin and lung involvement, although recently published data are contrasting $[48,49]$.
We also observed in the last years an increase in prescriptions of tocilizumab and intravenous globulins, representing an innovative vanguard approach for the treatment of refractory patients $[50,51]$.

The prevalence of use of vasoactive drugs, such as prostanoids, ERA and PDE-5 inhibitors, progressively increased along the study period. On the other hand, the number of patients treated with $\mathrm{CCB}$ dihydropyridine derivatives decreased during the time, even if $C C B$ was the class of vasoactive drugs with the highest observed prevalence of use in our study, confirming data recently published by Blagojevic et al. in a European multicentre study [52]. The gradual decreasing trend in prevalence of use of $\mathrm{CCB}$, may be explained with the necessity to avoid hypotensive attacks in patients already treated with ERA and PDE- 5 inhibitors.

The overall prevalence of use of prostanoids, recommended for PAH, digital ulcers and Raynaud's phenomenon, could be underestimated because before 2011 prostanoids were prescribed to inpatient cases only and the drug prescription database available for this study collects information only referred to outpatient prescriptions (see Methods section).

In general, this study demonstrates the importance of integrating data collected by a population-based registry with information from health administrative databases in defining a complete epidemiological profile of SSc. In particular, using a multi-database approach allows taking advantage to the greatest possible extent of the capacity of a population-based registry to collect almost all the cases diagnosed in a defined geographical area and, at the same time, exploiting information about comorbidities, therapies and vital status, routinely collected at local level.

This study also presents limitations. Firstly, some SScrelated complications could not be well defined, as the information derived from an administrative database (hospital discharge database) contains a lower level of details than disease-specific clinical data usually collected in hospital-based databases (e.g. scleroderma renal crisis is not defined by itself). Secondly, information about drug utilization do not take into account inpatient prescriptions (neither day-hospital prescriptions, except in the last years). This could lead to an underestimation of use for some drugs such as prostanoids, as described before. Another limitation could be that the diagnoses were made taking into account the ARA criteria until 2013 and EULAR/ACR from 2013 to 2017. This could lead to some difference in the classification of patients, although we did not observe a significant increased incidence after the introduction of the EULAR/ACR criteria. 


\section{Conclusion}

The study provides a complete epidemiological characterization of SSc, in terms of prevalence and incidence, survival, disease-related complications and comorbidities and therapies, by using a multi-database population-based approach. Prevalence estimate was 22.2 per 100,000 , with the highest prevalence observed for the age class over 65 years old (33.2 per 100,000, CI 95\% 29.637.3). SSc was found to be predominant in females $(86.7 \%$ on the total) with an overall sex ratio $F / M$ of 6.5 and an incidence of 2.8 and 0.5 per 100,000 for females and males, respectively. Despite this, males presented a more severe disease than females corresponding to a lower survival, with observed significant differences in pulmonary complications and metabolic comorbidities. DMARDs, ERA, and PDE-5 inhibitors were the drugs with the more pronounced increasing trend of prevalence of use in the 2008-2017 period.

The multi-database approach here presented is important in the field of rare diseases where it is often difficult to provide accurate epidemiological indicators, especially when cases are collected from hospital-based disease registries not covering a specific geographical area. A population-based registry can overcome this limit and, when exploited in synergy with administrative health databases, can be used to provide evidence related to disease outcomes and therapies and to assess the burden of the disease, relying on a significant cohort of cases.

Building an archive of data from multiple databases linking a cohort of patients to their comorbidities, clinical outcomes and survival, is important for the clinical management. The identification of complications or comorbidities is particularly relevant if the complication is associated with a negative clinical outcome or with a lower survival and, in this sense, the choice of an appropriate treatment for a specific complication or comorbidity can result in a better outcome.

\section{Supplementary Information}

The online version contains supplementary material available at https://doi. org/10.1186/s13023-021-01733-4.

Additional file 1. Definition of diseases associated with SSc (Table 1S) and investigated drugs (Table 2S).

\section{Abbreviations}

ARBs: Angiotensin II receptor blockers; ATC: Anatomical therapeutic chemical; CCB: Calcium channel blockers; Cl 95\%: Confidence interval 95\%; DDD: Defined daily dose; DMARDs: Disease-modifying antirheumatic drugs; ERA: Endothelin receptor antagonists; HR: Hazard ratio; ICD: International classification of diseases; IVIG: Polyclonal intravenous immunoglobulins; LOS: Length of stay; PAH: Pulmonary arterial hypertension; PDE-5: Phosphodiesterase-5; SSc: Systemic sclerosis.

\section{Acknowledgements}

We thank all the clinicians and health professionals throughout the rare disease network of Tuscany Region involved in collecting cases and providing health information. Rare Diseases Working Group: Cecilia Berni (Quality of Health Services and Clinical Networks, Tuscany Region, Italy), Federica Pieroni (Fondazione Toscana "Gabriele Monasterio", Rare Diseases Registry of Tuscany Congenital Anomalies Registry of Tuscany, Pisa, Italy), Sonia Marrucci (Fondazione Toscana "Gabriele Monasterio", Rare Diseases Registry of Tuscany - Congenital Anomalies Registry of Tuscany, Pisa, Italy). The Rare Diseases Working Group contributed to the extraction of data from the Rare Diseases Registry of Tuscany and provided secure data access to health regional databases. The Rare Diseases Registry of Tuscany is funded by the Tuscany Region - Direzione Diritti di cittadinanza e coesione sociale.

\section{Authors' contributions}

$A C, S B$, and MS conceptualized and designed the study. $A C$ and $S B$ performed the study and wrote the original draft of the manuscript. MS, FA, EB, MC, GE, BF, $S G, M M C, M M, P P, R P, E S, G S, A G T, F B$, and AP critically revised the manuscript. All the authors read and approved the final manuscript.

\section{Funding}

Not applicable.

\section{Availability of data and materials}

The data that support the findings of this study are available from Regione Toscana but restrictions apply to the availability of these data, which were used under license for the current study, and so are not publicly available. Data are however available from the authors upon reasonable request and with permission of Regione Toscana.

\section{Ethics approval and consent to participate}

Tuscany Region requests the delivery of an Informative Note to each patient (document available at: https://malattierare.toscana.it/static/media/uploa ds/INFORMATIVA.pdf) prior to their inclusion in the Rare Diseases Registry of Tuscany, according to Article 13 of Privacy Code (Legislative Decree 196/2003 Privacy Code). The Informative Note specifies that data of patients can be used for research and surveillance aims. Co-authors performing the study cannot in any way get the identity of patients and only aggregated results are published. All procedures performed in this study were in accordance with the Ethical Standards of the Ethical Committee of Azienda OspedalieroUniversitaria Pisana (the publication of the study was approved on the 27th October 2020).

\section{Consent for publication \\ Not applicable.}

\section{Competing interests}

The authors declare that they have no competing interests.

\section{Author details \\ ${ }^{1}$ Institute of Clinical Physiology, National Research Council, Via Moruzzi 1, Pisa, Italy. ${ }^{2}$ Rheumatology Unit, Department of Clinical and Experimental Medicine, University of Pisa, Pisa, Italy. ${ }^{3}$ Immunoallergology Unit, , Careggi University Hospital, Florence, Italy. ${ }^{4}$ Respiratory Diseases and Lung Transplantation, Department of Medical and Surgical Sciences and Neurosciences, University of Siena, Siena, Italy. ${ }^{5}$ Rare Dermatological Diseases Unit, USL Toscana Centro, Firenze, Italy. ${ }^{6}$ ERN-SKIN Diseases Centre, Department of Health Sciences, University of Florence, Firenze, Italy. ${ }^{7}$ Department of Experimental and Clinical Medicine, University of Firenze, Firenze, Italy. ${ }^{8}$ Rheumatology Unit, Depart- ment of Medical Sciences, Surgery and Neurosciences, University of Siena, "Le Scotte" Hospital, Siena, Italy. ${ }^{9}$ Rheumatology Unit, Department of Clinical and Experimental Medicine, University of Florence, Florence, Italy. ${ }^{10}$ Fondazi- one Toscana "Gabriele Monasterio," Pisa, Italy. ${ }^{11}$ Rheumatology Unit, Azienda Ospedaliero Universitaria Senese, Siena, Italy. ${ }^{12}$ Rheumatology Unit, A. Meyer Children's University Hospital, University of Florence, Florence, Italy. ${ }^{13}$ Clinical Immunology Unit, Department of Clinical and Experimental Medicine, Univer- sity of Pisa, Pisa, Italy.}

Received: 30 October 2020 Accepted: 3 February 2021

Published online: 17 February 2021 


\section{References}

1. Varga J, Trojanowska M. Kuwana N Pathogenesis of systemic sclerosis: recent insights of molecular and cellular mechanisms and therapeutic opportunities. J Scleroderma Relat Disord. 2017;2(3):137-52. https://doi. org/10.5301/jsrd.5000249.

2. Barsotti S, Orlandi M, Codullo V, Di Battista M, Lepri G, Della Rossa A, Guiducci S. One year in review 2019: systemic sclerosis. Clin Exp Rheumatol. 2019;37 Suppl 119(4):3-14.

3. Tyndall AJ, Bannert B, Vonk M, Airò P, Cozzi F, Carreira PE, Farge-Bancel D, Allanore Y, Müller-Ladner U, Distler O, lannone F, Pellerito R, Pileckyte M, Miniati I, Ananieva L, Gurman AB, Damjanov N, Mueller A, Valentini G, Riemekasten G, Tikly M, Hummers L, Henriques MJ, Caramaschi P, Scheja A, Rozman B, Ton E, Kumánovics G, Coleiro B, Feierl E, Szucs G, Von Mühlen CA, Riccieri V, Novak S, Chizzolini C, Kotulska A, Denton C, Coelho PC, Kötter I, Simsek I, de la Pena Lefebvre PG, Hachulla E, Seibold JR, Rednic S, Stork J, Morovic-Vergles J, Walker UA. Causes and risk factors for death in systemic sclerosis: a study from the EULAR Scleroderma Trials and Research (EUSTAR) database. Ann Rheum Dis. 2010:69(10):1809-15.

4. Zhong L, Pope M, Shen Y, Hernandez JJ, Wu L. Prevalence and incidence of systemic sclerosis: a systematic review and meta-analysis. Int J Rheum Dis. 2019;22(12):2096-107.

5. Ranque B, Mouthon L. Geoepidemiology of systemic sclerosis. Autoimmun Rev. 2010;9:A311-8.

6. Walker UA, Tyndall A. Geographical variation of disease manifestations in systemic sclerosis: a report from the EULAR Scleroderma Trials and Research (Eustar) group database. Ann Rheum Dis. 2009;68:856-62.

7. Alamanos Y, Tsifetaki N, Voulgari PV, Siozos C, Tsamandouraki K, Alexiou GA, Drosos AA. Epidemiology of systemic sclerosis in northwest Greece 1981 to 2002. Semin Arthritis Rheum. 2005;34(5):714-20.

8. Airò P, Tabaglio E, Frassi M, Scarsi M, Danieli E, Rossi M. Prevalence of systemic sclerosis in Valtrompia in northern Italy. A collaborative study of rheumatologists and general practitioners. Clin Exp Rheumatol. 2007;25:878-80.

9. Arias-Nuñez MC, Llorca J, Vazquez-RodriguezTR, Gomez-Acebo I, Miranda-Filloy JA, Martin J, Gonzalez-Juanatey C, Gonzalez-Gay MA. Systemic sclerosis in northwestern Spain: a 19-year epidemiologic study. Medicine (Baltimore). 2008;87(5):272-80.

10. Man A, Zhu Y, Zhang Y, Dubreuil M, Rho YH, Peloquin C, Simms RW, Choi HK. The risk of cardiovascular disease in systemic sclerosis: a populationbased cohort study. Ann Rheum Dis. 2013;72(7):1188-93.

11. Shenavandeh $S$, Naseri R. Assessment of hospitalization and mortality of scleroderma in-patients: a thirteen-year study. Reumatologia. 2017;55(4):163-8

12. Abbot S, McWilliams L, Spargo L, de Costa C, Ur-Rehman Z, Proudman S, Bossingham D. Scleroderma in Cairns: an epidemiological study. Intern Med J. 2019. https://doi.org/10.1111/imj.14376.

13. Carreira PE, Carmona L, Joven BE, Loza E, Andreu JL, Riemekasten G, Vettori S, Balbir-Gurman A, Airò P, Walker UA, Damjanov N, Matucci-Cerinic M, Ananieva LP, Rednic S, Czirják L, Distler O, Farge D, Hesselstrand R, Corrado A, Caramaschi P, Tikly M, Allanore Y, the EUSTAR co-authors. Gender differences in early systemic sclerosis patients: a report from the EULAR scleroderma trials and research group (EUSTAR) database. Clin Exp Rheumatol. 2018:36 Suppl 113(4):68-75.

14. Mihai C, Distler O, Gheorghiu AM, Constantin PI, Dobrota R, Jordan S, Smith V, Hachulla E, Henes J, Siegert E, Vettori S, Müller-Ladner U, Matucci Cerinic M, Allanore Y, EUSTAR. Incidence and risk factors for gangrene in patients with systemic sclerosis from the EUSTAR cohort. Rheumatology (Oxford). 2019;59(8):2016-23.

15. Noviani M, Saffari SE, Tan JL, Yip JWL, Teng GG, Law WG, Chan GYL, Santosa A, Lim AYN, Hong C, Ng SA, Tay ELW, Ruan W, Yap J, Low AHL. Mortality and hospitalization outcomes of interstitial lung disease and pulmonary hypertension in the Singapore systemic sclerosis cohort. Semin Arthritis Rheum. 2019. https://doi.org/10.1016/j.semarthrit .2019.11.005.

16. Pokeerbux MR, Giovannelli J, Dauchet L, Mouthon L, Agard C, Lega JC, Allanore Y, Jego P, Bienvenu B, Berthier S, Mekinian A, Hachulla E, Launay D. Survival and prognosis factors in systemic sclerosis: data of a French multicenter cohort, systematic review, and meta-analysis of the literature. Arthritis Res Ther. 2019;21(1):86.
17. Amoda O, Ravat V, Datta S, Saroha B, Patel RS. Trends in demographics, hospitalization outcomes, comorbidities, and mortality risk among systemic sclerosis patients. Cureus. 2018;10(5):e2628.

18. Butt SA, Jeppesen JL, Fuchs C, Mogensen M, Engelhart M, Torp-Pedersen C, Gislason GH, Jacobsen S, Andersson C. Trends in incidence, mortality, and causes of death associated with systemic sclerosis in Denmark between 1995 and 2015: a nationwide cohort study. BMC Rheumatol. 2018;2:36-46.

19. Kodra Y, Weinbach J, Posada-de-la-Paz M, Coi A, Lemonnier SL, van Enckevort D, Roos M, Jacobsen A, Cornet R, Ahmed SF, Bros-Facer V, Popa V, Van Meel M, Renault D, von Gizycki R, Santoro M, Landais P, Torreri P, Carta C, Mascalzoni D, Gainotti S, Lopez E, Ambrosini A, Müller H, Reis R, Bianchi F, Rubinstein YR, Lochmüller H, Taruscio D. Recommendations for improving the quality of rare disease registries. Int J Environ Res Public Health. 2018;15(8):1644.

20. Santoro M, Coi A, Lipucci Di Paola M, Bianucci AM, Gainotti S, Mollo E, Taruscio D, Vittozzi L, Bianchi F. Rare disease registries classification and characterization: a data mining approach. Public Health Genomics. 2015;18(2):113-22.

21. Rare Diseases Registry of Tuscany. http://malattierare.toscana.it.

22. Taruscio D (ed) II Registro Nazionale e i Registri Regionali/interregionali delle malattie rare. Rapporto anno 2011. Roma: Istituto Superiore di Sanità; 2011 (Rapporti ISTISAN 11/20)

23. Subcommittee for Scleroderma Criteria of the American Rheumatism Association Diagnostic and Therapeutic Criteria Committee. Preliminary criteria for the classification of systemic sclerosis (scleroderma). Arthritis Rheum. 1980:23:581-90.

24. van den Hoogen F, Khanna D, Fransen J, Johnson SR, Baron M, Tyndall A, Matucci-Cerinic M, Naden RP, Medsger TA Jr, Carreira PE, Riemekasten G, Clements PJ, Denton CP, Distler O, Allanore Y, Furst DE, Gabrielli A, Mayes MD, van Laar JM, Seibold JR, Czirjak L, Steen VD, Inanc M, Kowal-Bielecka O, Müller-Ladner U, Valentini G, Veale DJ, Vonk MC, Walker UA, Chung L, Collier DH, Ellen Csuka M, Fessler BJ, Guiducci S, Herrick A, Hsu VM, Jimenez S, Kahaleh B, Merkel PA, Sierakowski S, Silver RM, Simms RW, Varga J, Pope JE. 2013 classification criteria for systemic sclerosis: an American college of rheumatology/European league against rheumatism collaborative initiative. Ann Rheum Dis. 2013;72(11):1747-55.

25. Hughes M, Herrick AL. Systemic Sclerosis. Br J Hosp Med. 2019;80:530-6.

26. Cossio M, Menon Y, Wilson W, deBoisblanc BP. Life-threatening complications of systemic sclerosis. Crit Care Clin. 2002;18:819-39.

27. Avouac J, Kowal-Bielecka O, Landewe R, Chwiesko S. Miniati i, Czirjak L, Clements P, Denton C, Farge D, Fligelstone K, Földvari I, Furst DE, MüllerLadner U, Seibold J, Silver RM, Takehara K, Garay Toth B, Tyndall A, G Valentini, van den Hoogen F, Wigley F, Zulian F, Matucci-Cerinic M, EUSTAR Coauthors European League Against Rheumatism (EULAR) Scleroderma Trial and Research group (EUSTAR) recommendations for the treatment of systemic sclerosis: methods of elaboration and results of systematic literature research. Ann Rheum Dis. 2009;68(5):629-34.

28. Kowal-Bielecka O, Fransen J, Avouac J, Becker M, Kulak A, Allanore Y, Distler O, Clements P, Cutolo M, Czirjak L, Damjanov N, del Galdo F, Denton CP, Distler JHW, Foeldvari I, Figelstone K, Frerix M, Furst DE, Guiducci S, Hunzelmann N, Khanna D, Matucci-Cerinic M, Herrick AL, van den Hoogen F, van Laar JM, Riemekasten G, Silver R, Smith V, Sulli A, Tarner I, Tyndall A, Welling J, Wigley F, Valentini G, Walker UA, Zulian F, MüllerLadner U, EUSTAR Coauthors. Update of EULAR recommendations for the treatment of systemic sclerosis. Ann Rheum Dis. 2017;76:1327-39.

29. Fernández-Codina A, Walker KM, Pope JE. Treatment algorithms for systemic sclerosis according to experts. Arthritis Rheumatol. 2018;70(11):1820-8.

30. StataCorp. Stata Statistical Software: release 16. College Station: StataCorp LLC; 2019.

31. Motta F, Codullo V, Ramoni V, Cesari S, Ferrario G, Fiandrino G, Beneventi F, Rampello S, Johnsson H, Montecucco C, Graham GJ. Role of placental inflammatory mediators and growth factors in patients with rheumatic diseases with a focus on systemic sclerosis. Rheumatology (Oxford). 2020. https://doi.org/10.1093/rheumatology/keaa782.

32. Bergamasco A, Hartmann N, Wallace L, Verpillat P. Epidemiology of systemic sclerosis and systemic sclerosis-associated interstitial lung disease. Clin Epidemiol. 2019;11:257-73

33. Chu SY, Chen YJ, Liu CJ, Tseng WC, Lin MW, Hwang CY, Chen CC, Lee DD, Chen TJ, Chang YT, Wang WJ, Liu HN. Increased risk of acute myocardial 
infarction in systemic sclerosis: a nationwide population-based study. Am J Med. 2013;126(11):982-8.

34. Aviña-Zubieta JA, Man A, Yurkovich M, Huang K, Sayre EC, Choi HK. Early cardiovascular disease after the diagnosis of systemic sclerosis. Am J Med. 2016;129(3):324-31.

35. Proudman SM, Stevens WM, Sahhar J, Celermajer D. Pulmonary arterial hypertension in systemic sclerosis: the need for early detection and treatment. Intern Med J. 2007;37:485-94.

36. Pagkopoulou E, Arvanitaki A, Daoussis D, Garyfallos A, Kitas G, Dimitroulas T. Comorbidity burden in systemic sclerosis: beyond disease-specific complications. Rheumatol Int. 2019;39(9):1507-17.

37. Czirják L, Kumánovics G, Varjú C, Nagy Z, Pákozdi A, Szekanecz Z, Szucs G. Survival and causes of death in 366 Hungarian patients with systemic sclerosis. Ann Rheum Dis. 2008;67(1):59-63.

38. Lambova S. Cardiac manifestations in systemic sclerosis. World J Cardiol. 2014;6(9):993-1005.

39. Mecoli C, Purohit S, Sandorfi N, Derk CT. Mortality, recurrence, and hospital course of patients with systemic sclerosis-related acute intestinal pseudo-obstruction. J Rheumatol. 2014;41(10):2049-54.

40. Steen VC, Medsger TA. Case control study of corticosteroids and other drugs that either precipitate or protect from the development of scleroderma renal crisis. Arthritis Rheum. 1998;41:1613-9.

41. Blagojevic J, Legendre P, Matucci-Cerinic M, Mouthon L. Is there today a place for corticosteroids in the treatment of scleroderma? Autoimmun Rev. 2019;18:102403.

42. Angelopoulos TP, Tentolouris NK, Bertsias GK, Boumpas DT. Steroidinduced diabetes in rheumatologic patients. Clin Exp Rheumatol. 2014;32:126-30.

43. Tashkin DP, Elashoff R, Clements PJ, Goldin J, Roth M, Furst DE, Arriola E, Silver R, Strange C, Bolster M, Seibold JR, Riley DJ, Hsu VM, Varga J, Schraufnagel DE, Theodore A, Simms R, Wise R, Wigley F, White B, Steen V, Read C, Mayes M, Parsley E, Mubarak K, Connolly MK, Golden J, Olman M, Fessler B, Rothfield N, Metersky M, Scleroderma Lung Study Research Group. Cyclophosphamide versus placebo in scleroderma lung disease. N Engl J Med. 2006;354:2655-66.

44. Tashkin DP, Roth MD, Clements PJ, Furst DE, Khanna D, Kleerup EC, Goldin J, Arriola E, Volkmann ER, Kafaja S, Silver R, Steen V, Strange C, Wise R, Wigley F, Mayes M, Riley DJ, Hussain S, Assassi S, Hsu VM, Patel B, Phillips K, Martinez F, Golden J, Connolly MK, Varga J, Dematte J, Hinchcliff ME, Fischer A, Swigris J, Meehan R, Theodore A, Simms R, Volkov S, Schraufnagel DE, Scholand MB, Frech T, Molitor JA, Highland K, Read CA, Fritzler MJ, Kim GHJ, Tseng CH, Elashoff RM, Sclerodema Lung Study II Investigators. Mycophenolate mofetil versus oral cyclophosphamide in sclerodermarelated interstitial lung disease: scleroderma lung study II (SLS-II), a double-blind, parallel group, randomised controlled trial. Lancet Respir Med. 2016;4:708-19.
45. Denton C, Sweny P, Abdulla A, Black CM. Acute renal failure occurring in scleroderma treated with cyclosporin-A: report of three cases. Rheumatology. 1994;33:90-2.

46. Panopoulos S, Chatzidionysiou K, Tektonidou MG, et al. Treatment modalities and drug survival in a systemic sclerosis real-life patient cohort. Arthritis Res Ther. 2020;22(1):56. https://doi.org/10.1186/s1307 5-020-2140-3.

47. Bruni C, Praino E, Guiducci S, Bellando-Randone S, Furst DE, MatucciCerinic M. Hydroxychloroquine and joint involvement in systemic sclerosis: preliminary beneficial results from a retrospective case-control series of an EUSTAR Center. Joint Bone Spine. 2017;84(6):747-8.

48. Thiebaut M, Launay D, Rivière S, Mahévas T, Bellakhal S, Hachulla E, Fain O, Mekinian A. Efficacy and safety of rituximab in systemic sclerosis: French retrospective study and literature review. Autoimmun Rev. 2018;17:582-7.

49. Elhai M, Boubaya M, Distler O, Smith V, Matucci-Cerinic M, Alegre Sancho JJ, Truchetet ME, Braun-Moscovici Y, lannone F, Novikov PI, Lescoat A, Siegert E, Castellví I, Airó P, Vettori S, De Langhe E, Hachulla E, Erler A, Ananieva L, Krusche M, López-Longo FJ, Distler JHW, Hunzelmann N, Hoffmann-Vold AM, Riccieri V, Hsu VM, Pozzi MR, Ancuta C, Rosato E, Mihai C, Kuwana M, Saketkoo LA, Chizzolini C, Hesselstrand R, Ullman S, Yavuz S, Rednic S, Caimmi C, Bloch-Queyrat C, Allanore Y for EUSTAR network. Outcomes of patients with systemic sclerosis treated with rituximab in contemporary practice: a prospective cohort study. Ann Rheum Dis. 2019;78:979-987.

50. Khanna D, Denton CP, Jahreis A, et al. Safety and efficacy of subcutaneous tocilizumab in adults with systemic sclerosis (faSscinate): a phase 2, randomised, controlled trial. Lancet. 2016:387:2630-40.

51. Gomes JP, Santos L, Shoenfeld Y. Intravenous immunoglobulin (IVIG) in the vanguard therapy of Systemic Sclerosis. Clin Immunol. 2019;199:25-8. https://doi.org/10.1016/j.clim.2018.12.006.

52. Blagojevic J, Abignano G, Avouac J, Cometi L, Frerix M, Bellando-Randone S, Guiducci S, Bruni C, Huscher D, Jaeger VK, Lóránd V, Maurer B, Nihtyanova S, Riemekasten $\mathrm{G}$, Siegert E, Tarner $\mathrm{H}$, Vettori S, Walker UA, Czirják L, Denton CP, Distler O, Allanore Y, Müller-Ladner U, Moggi-Pignone A, Matucci-Cerinic M, Del Galdo F, EUSTAR co-workers. Use of vasoactive/ vasodilating drugs for systemic sclerosis (SSc)-related digital ulcers (DUs) in expert tertiary centres: results from the analysis of the observational real-life DeSScipher study. ClinRheumatol. 2020;39:27-36.

\section{Publisher's Note}

Springer Nature remains neutral with regard to jurisdictional claims in published maps and institutional affiliations.

Ready to submit your research? Choose BMC and benefit from:

- fast, convenient online submission

- thorough peer review by experienced researchers in your field

- rapid publication on acceptance

- support for research data, including large and complex data types

- gold Open Access which fosters wider collaboration and increased citations

- maximum visibility for your research: over $100 \mathrm{M}$ website views per year

At BMC, research is always in progress.

Learn more biomedcentral.com/submissions 